\title{
O significado da participação em visitas domiciliares pelo acadêmico de odontologia
}

\author{
Verônica Deneci*, Bianca Medeiros*, Diego Silva*, Katiana Vidal**, Leila Chevitarese*** \\ * Acadêmicos do Curso de Odontologia da Escola de Ciências da Saúde - \\ Professor José de Souza Herdy (UNIGRANRIO) \\ ** Professora adjunta mestre do Curso de Odontologia da UNIGRANRIO nas \\ disciplinas de Oclusão e Disfunção Temporomandibular \\ *** Professora Adjunto Doutor do Curso de Odontologia da Escola de Ciências \\ da Saúde da (UNIGRANRIO). Coordenadora do PRO-SAÚDE I- \\ UNIGRANRIO
}

\section{RESUMO}

Este estudo teve por finalidade analisar a percepção do estudante de odontologia quanto à necessidade da inclusão das visitas domiciliares realizadas na estratégia de promoção da saúde da família durante o curso de graduação. Para a coleta das informações, foram utilizados questionários fechados aplicados aos alunos da disciplina de Estágio Supervisionado I.

Descritores: Estratégia Saúde da Família, visita domiciliar, Ensino em odontologia.

\section{INTRODUÇÃO}

$\mathrm{O}$ ensino odontológico tem se fundamentado em atividades basicamente técnicas, voltadas para as clínicas das faculdades de odontologia. A resolução $\mathrm{CNE} / \mathrm{CES} \mathrm{n}^{\mathbf{0}}$ 3, que instituiu as Diretrizes Curriculares Nacionais para o ensino de graduação em Odontologia, enfatizou a importância do engajamento da educação superior e a saúde aos princípios do $\mathrm{SUS}^{4}$. Com base nessas Diretrizes Curriculares, inicia-se um processo de reforma curricular nos cursos de graduação em Odontologia, em que a inserção da saúde bucal no PSF exige um novo conceito da prática odontológica, e, consequentemente, surge a necessidade da formação de um profissional ideologicamente integrado à nova prática de saúde, que conheça o território adscrito à unidade em que vá atuar a fim de promover o cuidado contextualizado ${ }^{2}$.

A odontologia atual tem por objetivo humanizar as relações dos futuros profissionais de saúde com a comunidade e prepará-los a fim de prestar os cuidados de saúde com tais características. Para que isso aconteça, segundo Morita e Kriger ${ }^{10}$ (2003), há necessidade de se diversificar os cenários de prática de ensino, tais sejam: Unidades Básicas de Saúde, comunidades e domicílios, pois dessa forma além de oportunizar que a prática seja feita com "eficácia e eficiência", tal aproximação permitirá "melhor conhecimento da população que será atendida". Dessa forma, os futuros profissionais precisam aprender a criar vínculos e ter uma nova percepção do processo de saúde- doença.

$$
\text { Inglehart e } \text { Tedesco }^{7}
$$
ressaltaram esta necessidade quando afirmaram: 
Os cirurgiões dentistas precisam compreender a importância dos sistemas sociais para promoção da saúde bucal. Precisam mudar sua perspectiva de uma visão de tratar dentes para uma visão de tratar pessoas que são parte do sistema social.

Porém estas mudanças ocorrem gradualmente, visto que devem ocorrer a nível ideológico e cultural. Ainda, pode-se observar que profissionais e acadêmicos de odontologia apresentam dificuldades de integração junto à equipe de profissionais que atuam na Estratégia Saúde da Família (ESF) e junto à comunidade como um coletivo.

Vários mecanismos têm sido propostos para a integração dos acadêmicos em projetos comunitários, tais como trabalhos extramuros, visitas domiciliares e atendimentos do Programa Nacional de Reorientação da Formação Profissional em Saúde (Pró-Saúde).

O Pró-Saúde tem por objetivos incentivar transformações do processo de formação, gerar conhecimentos e prestar serviços à população, para abordagem integral do processo de saúde-doença ${ }^{3}$. O Curso de Odontologia da UNIGRANRIO foi contemplado com o Pró-Saúde I, o que permitiu não só aprofundar, bem como ampliar as transformações em seu processo ensino aprendizagem ${ }^{6}$.

Uma dessas ampliações foi a aproximação dos estudantes de Odontologia com as Equipes que atuam nas UBS de Jardim Gramacho em Duque de Caxias, RJ.

Lá, a UNIGRANRIO atua em parceria com a Secretaria de Saúde com o apoio do Pró-Saúde. É nesse contexto que as visitas domiciliares dentro do Curso de Odontologia têm sido utilizadas como um instrumento de abordagem das famílias e seu objetivo foi aproximar os estudantes da vida familiar, fazendo-os entrar em contato com a realidade (por vezes desconhecida) de seus membros e de sua dinâmica, a fím de obter diagnóstico e, assim, contribuir para diminuir - ou mesmo sanar - os problemas de saúde. Através desta proximidade, busca-se contribuir para uma formação profissional mais humanística, o que não se observa no aprendizado de uma Odontologia tradicional onde o centro do conhecimento é o elemento dentário ${ }^{13}$.

O objetivo do presente trabalho foi identificar o significado que os acadêmicos de odontologia atribuem às visitas domiciliares no início de sua capacitação para o processo de trabalho em Saúde da Família em parceria com Equipes que já atuam na ESF.

\section{METODOLOGIA}

Este trabalho foi realizado por acadêmicos do Curso de Odontologia da UNIGRANRIO, sob a orientação das professoras da disciplina de Estágio Supervisionado. Foi utilizado um questionário com 11 perguntas fechadas e 1 aberta. Os alunos foram convidados a participar da pesquisa no final do semestre letivo; após terem lido e compreendido o objetivo do estudo, somente aqueles que expressaram a sua autorização, assinando o termo de consentimento livre e esclarecido, colaboraram no estudo.

Para tal, se tomou como base os conhecimentos adquiridos nas visitas domiciliares realizadas no trabalho da ESF no Bairro de Jardim Gramacho, ao final do período de cinco meses. Esse período envolve o tempo de preparo do acadêmico para o início das atividades em campo de estágio com capacitações teóricas e a sua vivência em campo prático, atuando com 
profissionais da rede que já trabalham na ESF.

Este trabalho foi submetido à apreciação do comitê de ética em pesquisa da Universidade do Grande Rio e aprovado sob de $\mathrm{n}^{\circ}$ de protocolo $00140.317 .000-07$.

\section{RESULTADOS}

Foram analisados 37 questionários respondidos pelos estudantes do $4^{\circ}$ período do Curso de Odontologia na Disciplina de Estágio Supervisionado I, determinando assim a coleta dos dados. Na Tabela 1 abaixo, podem ser vistos os resultados analisados por perguntas respondidas pelos acadêmicos.

Tabela 1 - Questionário respondido pelos acadêmicos do $4^{\circ}$ período do Curso de Odontologia na Disciplina de Estágio Supervisionado I da UNIGRANRIO

\begin{tabular}{|c|c|c|c|c|}
\hline Perguntas & Sim & $\%$ & Não & $\%$ \\
\hline $\begin{array}{l}\text { 1) Você já havia participado de visitas } \\
\text { domiciliares que são realizadas naESF } \\
\text { anteriormente? }\end{array}$ & 3 & $8,1 \%$ & 34 & $91,9 \%$ \\
\hline $\begin{array}{l}\text { 2) Você sabia que dentistas participavam } \\
\text { das visitas domiciliaresnaESF? }\end{array}$ & 30 & $81,1 \%$ & 7 & $18,9 \%$ \\
\hline $\begin{array}{l}\text { 3) Você acha válida a participação de } \\
\text { dentistas/acadêmico de odontologia em } \\
\text { visitas domiciliares? }\end{array}$ & 32 & $86,5 \%$ & 5 & $13,5 \%$ \\
\hline $\begin{array}{l}\text { 4) Seafirmativa, explique (Considerações } \\
\text { abaixo descritas) }\end{array}$ & - & - & - & - \\
\hline $\begin{array}{l}\text { 5) Você tinha noção de que, como } \\
\text { acadêmico de odontologia, você faria visitas } \\
\text { domiciliares? }\end{array}$ & 20 & $54 \%$ & 17 & $46 \%$ \\
\hline $\begin{array}{l}\text { 6) Você observou proveito para sua vida } \\
\text { profissional? }\end{array}$ & 32 & $86,5 \%$ & 5 & $13,5 \%$ \\
\hline $\begin{array}{l}\text { 7) Você gostou de atuar em uma equipe } \\
\text { multidisciplinar? }\end{array}$ & 30 & $81,1 \%$ & 7 & $18,9 \%$ \\
\hline $\begin{array}{l}\text { 8) Você viu algum proveito nesta interação } \\
\text { multidisciplinar para sua vida profissional? }\end{array}$ & 31 & $83,8 \%$ & 6 & $16,2 \%$ \\
\hline $\begin{array}{l}\text { 9) Você sabia que existiam outros } \\
\text { profissionais nestas visitas? }\end{array}$ & 27 & $73 \%$ & 9 & $27 \%$ \\
\hline $\begin{array}{l}\text { 10) Você imaginava como seriam as } \\
\text { residências visitadas? }\end{array}$ & 17 & $46 \%$ & 20 & $54 \%$ \\
\hline $\begin{array}{l}\text { 11) Vocêse surpreendeu com a realidade } \\
\text { que observou? }\end{array}$ & 20 & $54 \%$ & 17 & $46 \%$ \\
\hline $\begin{array}{l}\text { 12) Você acha que esta realidade tem a ver } \\
\text { comos problemas de saúde bucal? }\end{array}$ & 34 & 91,9\% & 3 & $8,1 \%$ \\
\hline
\end{tabular}

Considerando o questionário aplicado e utilizando-se como base a pergunta de $n^{0} 3$ - que visava saber se a participação de dentistas/acadêmico de odontologia em visitas domiciliares era considerada válida - foi pedido, na pergunta $\mathrm{n}^{\mathrm{o}}$ 4, que os acadêmicos explicassem o motivo, caso a resposta tivesse sido afirmativa na pergunta anterior. Os resultados sistematizados podem ser observados no Gráfico 1 abaixo apresentado. 
Gráfico 1 - Significado da Participação do Acadêmico em Visita Domiciliar

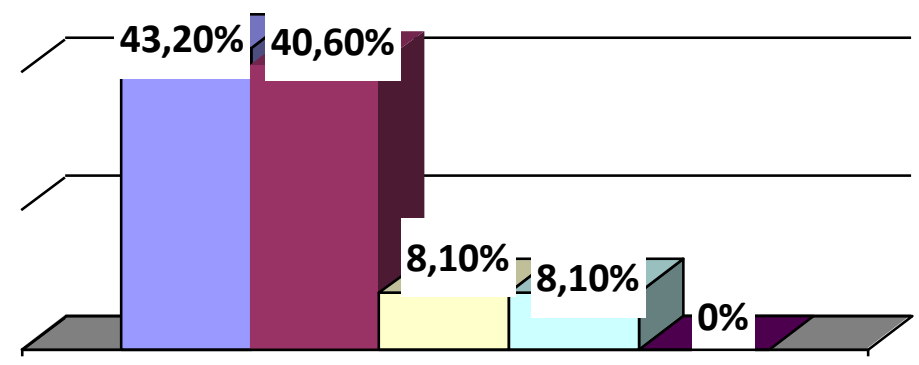

\begin{tabular}{|l|}
\hline Atividade Humanística \\
Atividade que Ajuda na Resolução dos Problemas \\
$\square$ Atividade Técnica \\
$\square$ Outros \\
$\square$ Atividade que pode ser dispensada
\end{tabular}

\section{DISCUSSÃO}

A partir da Carta de Ottawa, saúde passou a ser compreendida como sinônimo de qualidade de vida fazendo com que a prática de saúde fosse exercida no território em que as pessoas vivem, se realizam e adoecem $(\mathrm{ONU})^{11}$. Assim, o cirurgiãodentista formado ou em formação para dar conta dessa prática deverá incluir em sua relação com o indivíduo que está sob seu cuidado, a escuta ativa do que ele traz como necessidades de saúde e se esforçar para compreender o que muitos desses não conseguem verbalizar, modificando sua percepção durante o ato de cuidar $^{5}$. No presente estudo, pode ser observado que a percepção dos acadêmicos de Odontologia está sendo modificada e, que tais mudanças estão acontecendo em nível ideológico/comportamental.

Os acadêmicos têm consciência de que a visita domiciliar é uma ferramenta que ajuda na resolução dos problemas (40,60\% - Gráfico 1) pelo fato de terem associado a realidade de vida das pessoas com o seu contexto bucal (91,9\% - Tabela 1). Guardam-na, ainda, como atividade humanística (43, 20\% - Gráfico 1). Nota-se que, a visita domiciliar começa a ser citada como atividade técnica e que não pode ser dispensada pelos acadêmicos que participaram do estudo $(8,10 \%$ em ambos os casos - Gráfico 1).

A visita domiciliar ao ser classificada como atividade humanística ajudou a capacitar os acadêmicos de Odontologia, segundo Pessotti ${ }^{12}$ (1996), para "ver e ouvir o homem que está vitimado pela doença e, por isso traz ao consultório o corpo doente". O autor lembra que a formação humanística não começa no curso ofertado na universidade, porque os valores ou significados das coisas, eventos ou pessoas, são produtos da experiência pessoal de cada um (sofrimentos $e$ prazeres, sustos e alegrias). Assim, é necessário que a manutenção desse olhar seja estimulada, no entanto, é importante que seja compreendido como um corpo doente dentro de um contexto que precisa ser conhecido pelo profissional de saúde para que este possa prestar-lhe cuidado, com competência técnica. Esse olhar 
técnico é transformado pelos acadêmicos de Odontologia ao longo de sua caminhada pelos Estágios Supervisionados na UNIGRANRIO, na medida em que se deixam transformar pelo processo de capacitação impulsionado pelo Pró-Saúde.

Canalli et al. ${ }^{5}$ (2012) afirmam que o acadêmico, ao entrar em contato com o contexto de vida do seu paciente, passa a compreender toda a rotina de vida do mesmo, todas as suas dificuldades para a manutenção de uma vida digna. Concluem sobre esse assunto que essa aproximação traz à tona o aspecto da humanidade que é inerente ao indivíduo e que quase sempre fica esquecida pelos professores, pelos próprios acadêmicos, pelos cirurgiõesdentistas ou por qualquer outro profissional de saúde em suas respectivas práticas diárias.

O presente trabalho mostrou que $8,10 \%$ dos estudantes entrevistados classificam a visita domiciliar como atividade técnica. $\mathrm{O}$ trabalho de Botelho e Espirito Santo ${ }^{1}$ (2008) mostrou que 85,42\% dos alunos que cumpriram a atual matriz e responderam o questionário por adesão voluntária sentem-se aptos a trabalhar na Atenção Básica na lógica da Estratégia Saúde da Família e em outros cenários. Cabe lembrar que os participantes da presente pesquisa ainda estão no início do sua capacitação junto ao processo de trabalho em Saúde da Família ( $4^{\circ}$ período do Curso de Odontologia).

Por meio da visita domiciliar, trabalha-se a proteção da saúde lançando mão da prática educativa, a fim de se desenvolverem potencialidades individuais e coletivas no enfrentamento da doença. Com isso, objetiva-se a autonomia da família e de seus membros na resolução de seus problemas ${ }^{14}$. Esse pensamento está em acordo com os dos acadêmicos ao apontarem a visita domiciliar como ferramenta que ajuda na resolução dos problemas (40,60\% - Gráfico 1).

A percepção dos alunos quanto à importância das visitas domiciliares em sua formação profissional ficou nítida $(86,5 \%)$, assim como o reconhecimento da enriquecedora experiência de atuar juntamente com profissionais de outras áreas $(83,8 \%)$. Esses dados estão de acordo com o estudo realizado por Matos e Tomita $^{8}$ (2004), em que formadores e estudantes de três instituições de ensino foram entrevistados a respeito do novo modelo dos projetos pedagógicos visando uma articulação entre a educação superior e a saúde, enfatizando os princípios do SUS. Neste estudo, os autores concluem que: "De maneira geral, os estudantes concordam que se trata de um importante passo para a expansão da Odontologia, com repercussões sobre o quadro de saúde da população brasileira".

Os mesmos autores apresentam o relato de um dos estudantes entrevistados em que este afirma que, por mais que possa imaginar, a realidade encontrada em campo ainda o surpreende. Este relato exprime os números encontrados no presente estudo, quando $54 \%$ dos alunos afirmam terem se surpreendido com a realidade encontrada nas visitas domiciliares. É intenção da atividade em campo apresentar ao aluno uma realidade desconhecida, a fim de que haja uma conscientização da importância de sua participação na ESF, contribuindo para a sua formação ${ }^{9}$. 


\section{CONCLUSÕES}

As visitas domiciliares se mostraram como importante ferramenta no ensino do cuidado em saúde, tornando-o contextualizado e humanizado.

O Pró-Saúde foi um forte indutor de mudanças na forma de ensinar no Curso de Odontologia da UNIGRANRIO desde sua implantação.

\section{REFERÊNCIAS}

1. Botelho T, Espírito Santo A. Relato de Um Diferencial. Revista Rede de Cuidados em Saúde. 2008; 2(2):1-2.

2. Brasil. Ministério da Educação. Resolução $n^{\circ}$ CNE/CES 3/2002 de 19 de fevereiro de 2002. Institui as Diretrizes Curriculares Nacionais dos Cursos de Farmácia e Odontologia. Diário Oficial, Brasília, 04 mar 2002, seção 1, p. 10.

3. Brasil. Ministério da Saúde. Ministério da Educação. Pró-saúde: Programa Nacional de Reorientação da Formação Profissional em Saúde / Ministério da Saúde, Ministério da Educação. Brasília: Editora do Ministério da Saúde, 2007. 78 p.

4. Câmara de Educação Superior, Conselho Nacional de Educação. Resolução CNE/CES 3, de 19 de fevereiro de 2002. http://www.mec.gov.br/cne/pdf/CES03 2002.pdf (acessado em 07/01/2014).

5. Canalli CSE, Silveira RG, Miasato, JM, Chevitarese, L. Humanização na Relação CirurgiãoDentista-Paciente. Rev. Odontol. Univ. Cid. São Paulo. 2012 Set-Dez; 24(3):220-5.

6. Chevitarese L, Carvalho SC. Processo de Significação da Matriz Curricular como Rede de Cuidados em Saúde em
Odontologia. Revista Rede de Cuidados em Saúde. 2010; 4(2):1-9.

7. Inglehart $\mathrm{M}$, Tedesco LA. Behavioral research related to oral hygiene practices: A new century model of oral health promotion. Periodontology. 1995; 8:15-23.

8. Matos PES, Tomita NE. A inserção da saúde bucal no Programa Saúde da Família: da universidade aos pólos de capacitação. Cad. Saúde Pública, Rio de Janeiro, 2004 Nov-Dez; 20 (6):1538-1544.

9. Medeiros UV. Experiências inovadoras no ensino de odontologia. Odontólogo Moderno. 1997 Jan/Fev; 24(1):9-12.

10. Morita MC, Kriger L. Mudanças nos cursos de Odontologia e a interação com o SUS. Revista da ABENO. 2003; $4(1): 17-21$.

11. ONU Organização das Nações Unidas. Declaração universal dos direitos humanos 1948 [cited 2014 Feb 9]. Available from: http://portal.mj.gov.br/sedh/ct/legis_int ern/ddh_bib_inter_universal.htm.

12. Pessotti I. A formação humanística do médico. Medicina Ribeirão Preto. 1996 Out/Dez; 29:440-448.

13. Sanchez HF, Drumond MM, Vilaça EL. Adequação de recursos humanos ao PSF: percepção de formandos de dois modelos de formação acadêmica em odontologia. Ciênc. saúde coletiva. Rio de Janeiro, 2008 Mar/Abr; 13(2).

14. Torres HC, Roque C, Nunes C. Visita Domiciliar: Estratégia Educativa para o Autocuidado de Clientes Diabéticos na Atenção Básica. Rev. Enferm. UERJ, Rio de Janeiro, 2011 jan/mar; 19(1):8993. 


\section{ABSTRACT}

The meaning of participation in visit home by academic dentistry

The aim of this study was to evaluate the student's perception of dentistry, as the need for inclusion in home visits conducted in the strategy of family health. For the collection of information were used closed questionnaires applied to students of the discipline of supervised probation I.

Descriptors: Family Health Strategy, Home visit, Dentistry teaching. 